\title{
Exendin-4 effects on islet volume and number in the mouse pancreas
}

\author{
Khorsandi L, Nejad-Dehbashi F \\ Cell and Molecular Research Center, Ahvaz Jundishapur University of Medical Sciences, Ahvaz, Iran. \\ layasadat@yahoo.com
}

\begin{abstract}
The aim of this study was to evaluate Exendin-4 (EX-4) effect on islet volume and number in the mouse pancreas. Thirty-two healthy adult male NMRI mice were randomly divided into control and experimental groups. EX-4 was injected intraperitoneally (i. p.) at the doses of 0.25 (E1 group), 0.5 (E2 group), and $1 \mu \mathrm{g} / \mathrm{kg}$ (E3 group), twice a day for seven consecutive days. One day after the final injection, the mice were sacrificed, and pancreas from each animal was dissected out, weighed, and fixed in $10 \%$ formalin for measurement of pancreas, and islet volume and islet number by stereological assessments. There was a significant increase in the weight of pancreases in E3 groups. Islet and pancreas volumes in E1 and E2 groups were not changed compared to control group. E3 group showed a significant increase in islet and pancreas volume $(p<0.05)$. There were no significant changes in the total number of islets in three experimental groups. The results revealed that EX-4 increased pancreas and islet volume in non-diabetic mice. The increased total islet mass is probably caused by islet hypertrophy without the formation of additional islets (Fig. 5, Ref. 35). Text in PDF www.elis.sk. Key words: exendin-4, pancreas, islet hypertrophy, stereology, mice.
\end{abstract}

Glucagon-like peptide-1 (GLP-1) is a peptide secreted from the gut in response to food. It acts directly on $\beta$ cells, enhancing the effect of glucose in stimulating insulin secretion from these cells. When administered to diabetic mice, GLP-1 lowers blood glucose levels and stimulates insulin secretion (1). In addition, GLP-1 increases the $\beta$-cell mass by inducing the differentiation and neogenesis of ductal progenitor cells into islet endocrine cells (2, 3 ). In a previous in vitro study, it had been showed that GLP-1 is capable of enhancing fetal pig $\beta$-cell differentiation from progenitor epithelial cells as well as initiating their functional maturation in islet-like cell clusters (4).

Exendin-4, a long-acting GLP-1 receptor (GLP-1R) agonist, binds to and activates the GLP-1R with the same potency as GLP-1 (1). Exendin-4 (EX-4) is resistant to the enzyme dipeptidyl peptidase 4 (DPT-IV), which is present in serum. GLP-1 is rapidly metabolized by DPP-IV (5). It has been reported previously that EX-4 is capable of stimulating both the differentiation of $\beta$ cells from ductal progenitor cells and proliferation of $\beta$ cells when given to rats and humans (6-8).

Previous studies on EX-4 action were mostly done on diabetic rodent models. However, some studies demonstrate that EX-4 has beneficial effect in non-diabetic animals. It has been reported that

Cell and Molecular Research Center, Ahvaz Jundishapur University of Medical Sciences, Ahvaz, Iran

Address for correspondence: L. Khorsandi, Cell and Molecular Research Center, Faculty of Medicine, Ahvaz Jundishapur University of Medical Sciences, Ahvaz, Iran, P.O. Box: 61335, Ahvaz, Iran

Acknowledgement: This research was supported by a Grant (CM-004) from the research council of the Ahvaz Jundishapur University of Medical Sciences in 2011.
EX-4 causes weight loss (9-11). In the placebo-controlled component of the pivotal trials, which lasted 30 weeks, the mean weight reduction ranged between 1 and $3 \mathrm{~kg}$ compared with placebo. In open-label extensions, the weight continued to decline over two years of treatment, up to $5 \mathrm{~kg}$ from baseline $(12,13)$.

It is known that EX-4 can pass through the blood-brain barrier (8) and exert central effects, including promotion of neurotropic or neuroprotective actions $(14,15)$ and enhancement of cognitive functions (16). These findings suggest that GLP-1 receptor stimulation in the central nervous system plays a critical role in regulating neuronal plasticity and cell survival. Vella et al (2003) reported that EX-4 and GLP-1 increase cortisol secretion in human subjects. However, none of them alters insulin action in non-diabetic human subjects (17). Ranta et al (2006) demonstrated that EX-4 protects against glucocorticoid-induced mouse beta-cells or INS-1 cells apoptosis (18). Chen et al showed that EX-4 can inhibit rat cardiomyocyte apoptosis early after scald injury possibly by suppressing caspase-3 activity in the myocardium (19).

In spite of numerous experimental studies about EX-4 effects on various tissues in nondiabetic subjects, there is only one study about its effects on pancreas (20). In present study, EX-4 effect on islet volume and number in the mouse pancreas was investigated by using stereological procedures.

\section{Materials and methods}

Animals

In this study, 32 healthy and adult male NMRI (Naval Medical Research Institute) mice (6-8 weeks old, 25-30 g) were used. The animals were obtained from Ahvaz Jundishapur University 


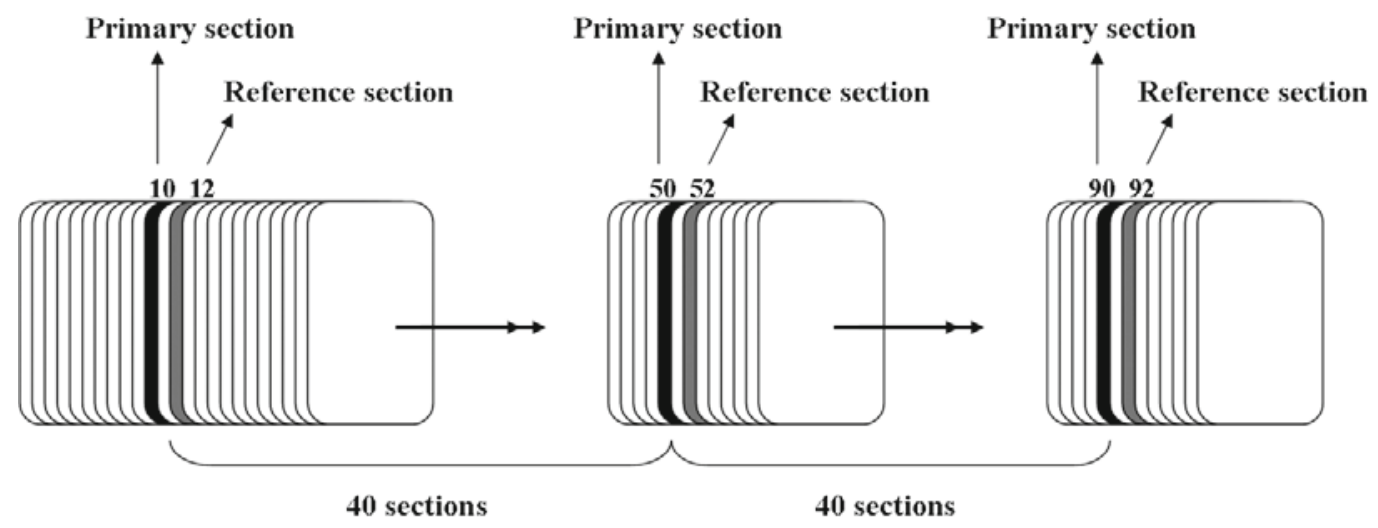

Fig. 1. Sampling method of histological sections is shown.

of Medical Sciences, Laboratory Animal Research Center. This study was approved by the ethics committee of Jundishapur University and carried out in an ethically proper way by following the guidelines provided. The animals were kept under standard laboratory conditions ( $12 \mathrm{~h}$-dark and $12 \mathrm{~h}$-light cycle, relative humidity of $50 \pm 5 \%$ and $22 \pm 3{ }^{\circ} \mathrm{C}$ ) for at least one week before the experiment and those conditions were preserved until the end of the experiment. Animal cages were kept clean, and commercial food (pellet) and water were provided ad libitum.

\section{Experimental design}

The mice were randomly divided into control and experimental groups, all of which contained eight animals. EX-4 (Sigma) was dissolved in distilled water and was injected intraperitoneally (i.p.) at the doses of 0.25 (E1 group), 0.5 (E2 group), and $1 \mu \mathrm{g} / \mathrm{kg}$ (E3 group), twice a day for seven consecutive days. The dosage and duration of treatment with EX-4 was selected according to previous studies that demonstrated beneficial effect of EX-4 on focal cerebral ischemia-induced infarction in rats (21). One day after the final injection, the mice were sacrificed by cervical dislocation, and pancreas from each animal was dissected out, weighed, and fixed in $10 \%$ formalin.

\section{Stereological assessments}

\section{Histology and sampling of sections}

Each pancreas was embedded randomly in paraffin and sectioned exhaustively into $5 \mu \mathrm{m}$-thick sections. Figure 1 illustrates the sampling of sections. Three sections were collected onto each glass slide. With a random start between the first 40 sections, every 40th section was sampled (the primary sections). In addition, two sections ahead of every primary section were sampled as a reference section. Because every section was $5 \mu \mathrm{m}$ thick, it follows that there was $200 \mu \mathrm{m}$ between the primary sections and $10 \mu \mathrm{m}$ between a primary section and a corresponding reference section. All primary and reference sections were stained with hematoxylin and eosin (H \& E).

\section{Microscopes and equipment}

The sections were analyzed at 400x magnification by a MP3, $\mathrm{Nr} 3437$ microscope (PZO, Poland) equipped with a projecting arm to project the image onto a monitor which was attached to the microscope. The applied probes used for the stereological examinations (point-counting grid or counting frame as described below) were superimposed to the monitor so that the microscope projected the image onto the grid. We used two microscopes at the same time for counting the total number of islets in primary and reference sections.

\section{Total volumes of islets and pancreas}

Using step-lengths of $950 \mu \mathrm{m}$ in the $x$-direction $(\Delta x)$ and 750 $\mu \mathrm{m}$ in the $y$-direction $(\Delta y)$, all primary sections from each pancreas were systematically examined. A point-counting grid with 108 points, 1 of them encircled, was applied (Fig. 2A). Moving through all primary sections from the pancreata, we counted how many times 1 of the 108 points hit an islet. An islet was defined as a cluster of cells with a minimum of three visible nuclei displaying the normal characteristics of islet endocrine cells (pale cytoplasm with approximately spherical nuclei). Simultaneously, we counted how many times the encircled point hit the pancreatic tissue (exocrine pancreatic tissue, ducts, vessels, islets, etc.). The values for the total volume of pancreas and islets of Langerhans were then calculated based on the Cavalieri principle $(22,23)$.
A

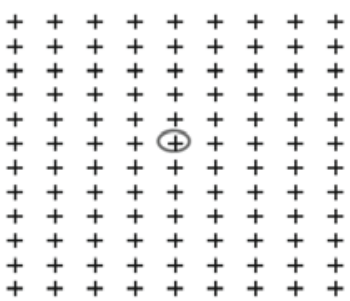

B

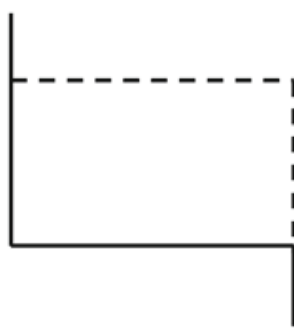

Fig. 2. Point counting grade (A) and unbiased counting frame (B). 
1) $\mathrm{V}($ pan $)=\mathrm{a} / \mathrm{p}($ pan $) \times \mathrm{N}(\mathrm{p}-\mathrm{p}) \times \mathrm{T} \times \sum \mathrm{P}($ pan $)=0.1425 \mathrm{~mm} 3 \times \sum \mathrm{P}($ pan $)$

where $\mathrm{V}$ (pan) is the total volume of pancreas, $\mathrm{a} / \mathrm{p}$ (pan) is the area per point (in this case $\Delta x \times \Delta y$ because only one point in the grid was used to count points that hit pancreas), $N(p-p)$ is the number of sections between the primary sections ( 50 sections in this case), $\mathrm{T}$ is the section thickness $(5 \mu \mathrm{m})$, and $\sum \mathrm{P}$ (pan) is the total number of points that hit pancreas.

2) $\mathrm{V}($ isl $)=\mathrm{a} / \mathrm{p}($ isl $) \times \mathrm{N}(\mathrm{p}-\mathrm{p}) \times \mathrm{T} \times \sum \mathrm{P}($ isl $)=1.319 \times 10^{3} \mathrm{~mm}^{3} \times \sum \mathrm{P}($ isl $)$

where $\mathrm{V}$ (isl) is the total volume of islets, $\mathrm{a} / \mathrm{p}$ (isl) is the area per point (in this case $\Delta x \times \Delta y / 99$ because there were 99 points in the grid used to count points that hit islets), and $\sum \mathrm{P}$ (isl) is the total number of points that hit the islets.

Tissue shrinkage influences all stereologic size estimators whether it is distance, surface area, or volume. There is no exact unbiased way to obtain information about tissue deformation during tissue fixation and processing. The area of a piece of pancreas tissue before and after fixation/processing may be estimated, and the tissue shrinkage can be calculated as (24):

$1-\left(\frac{\text { A-after }}{\text { A-before }}\right)^{1.5}$

\section{Total number of islets}

In another session, the sampling within the primary sections was performed, but an unbiased counting frame (Fig. 2B) was now attached to the monitor. The rules of the counting frame define objects completely outside the frame or objects that touch the exclusion lines (full lines in Fig. 2) as being outside the frame, whereas objects that are completely within the frame or touch only the inclusion lines (the dashed lines in Fig. 2) are defined as being within the frame. We applied the disector principle (Sterio, 1984) to count the islets. Whenever an islet profile was sampled by the counting frame, the corresponding position in the reference section was located with the other microscope, and we determined whether the islet was also visible in the reference section. An islet was counted if it appeared in the primary section but not in the reference section. Because the sampling of sections as well as the within section sampling were performed with known sampling fractions, the total number of islets can be calculated according to the fractionator principle $(22,23)$ from:

$\mathrm{N}($ isl $)=\frac{\mathrm{N}(\mathrm{p}-\mathrm{p})}{\mathrm{N}(\mathrm{p}-\mathrm{r})} \times \frac{\Delta \mathrm{x} \times \Delta \mathrm{y}}{\mathrm{A}(\text { frame })} \times \sum \mathrm{Q}^{-}($isl $)=34.53 \times \sum \mathrm{Q}^{-}$(isl)

where $\mathrm{N}$ (isl) is the total number of islets in the pancreas, $\mathrm{N}$ $(p-p)$ is the number of sections between the primary sections, $N$ $(p-r)$ is the number of sections between a primary section and the corresponding reference section (two in this case), $\Delta x$ and $\Delta$ $y$ are the step lengths, $\mathrm{A}$ (frame) is the area of the counting frame corrected for magnification $\left(412.674 \mu \mathrm{m}^{2}\right)$, and $\Sigma \mathrm{Q}^{-}$(isl) is the total number of islets counted in one pancreas (23).
RNA preparation and Reverse Transcription Polymerase Chain Reaction (RT-PCR)

Isolated pancreases are either used immediately or snap frozen in liquid nitrogen and stored at $-80^{\circ} \mathrm{C}$ until use. Using the RNeasy Mini kit (Qiagen), RNA was isolated from the tissues according to manufacturer's instructions. RT-PCR was performed using a One-Step RT-PCR kit (Qiagen) which contains reverse transcriptase to synthesize cDNA from RNA isolated and DNA polymerase for PCR. RT-PCR conditions consisted of a 30-minute step at 50 ${ }^{\circ} \mathrm{C}$ to allow the reverse transcriptase activity followed by $15 \mathrm{~min}$ at $95{ }^{\circ} \mathrm{C}$ to deactivate the reverse transcriptase and activate the Taq polymerase present in the enzyme mixture. The PCR process consisted of $6 \mathrm{~s}$ at $94{ }^{\circ} \mathrm{C}$ (denaturing step), $30 \mathrm{~s}$ at the annealing temperature $\left(55^{\circ} \mathrm{C}\right)$, and a 45 -second step at $72{ }^{\circ} \mathrm{C}$ for extension with all steps being repeated for 30 cycles. A final extension step lasted $10 \mathrm{~min}$ at $72{ }^{\circ} \mathrm{C}$.

Primer sequences were as follows with the expected product length: Glut-2, sense 5' CAGCTGTCTCTGTGCTGCTTGT 3', antisense 5' GCCGTCATGCTCACATAACTCA 3' (150 bp); Insulin, sense 5' TCTTCTACACACCCATGTCCC 3', antisense 5' GGTGCAGCACTGATCCAC 3', (149 bp); and GAPDH, sense 5' CTC TGGTGGACCTCATGGCCTAC 3', antisense 5' CAGCAACTGAGGGCCTCTCT 3' (105 bp) was used as housekeeping gene (25).

\section{Statistical analysis}

The data were analyzed using one-way ANOVA followed by Post hoc LSD test and presented as the mean \pm SD. $P<0.05$ was considered significant.

\section{Results}

As expected, mean body weight was equal in the four groups. Weight of pancreases in E1 and E2 groups were similar to that in control group. There was a significant increase in the relative pancreas weight / body weight in E3 group (Fig. 3).

The present study confirms $30 \%$ of tissue shrinkage in paraffin embedding. This shrinkage was considered when the final results were reported.

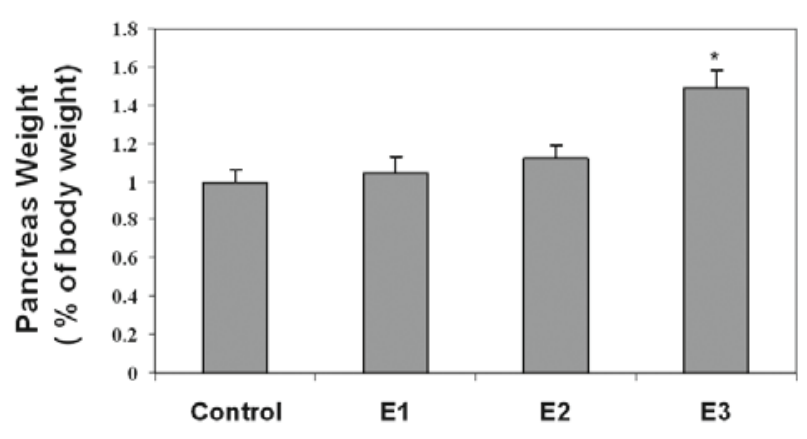

Fig. 3. The relative pancreas weight / body weight in control and experimental groups. Values are expressed as means \pm SD for 8 mice. * $\mathrm{p}<0.05$ compared to control group. 

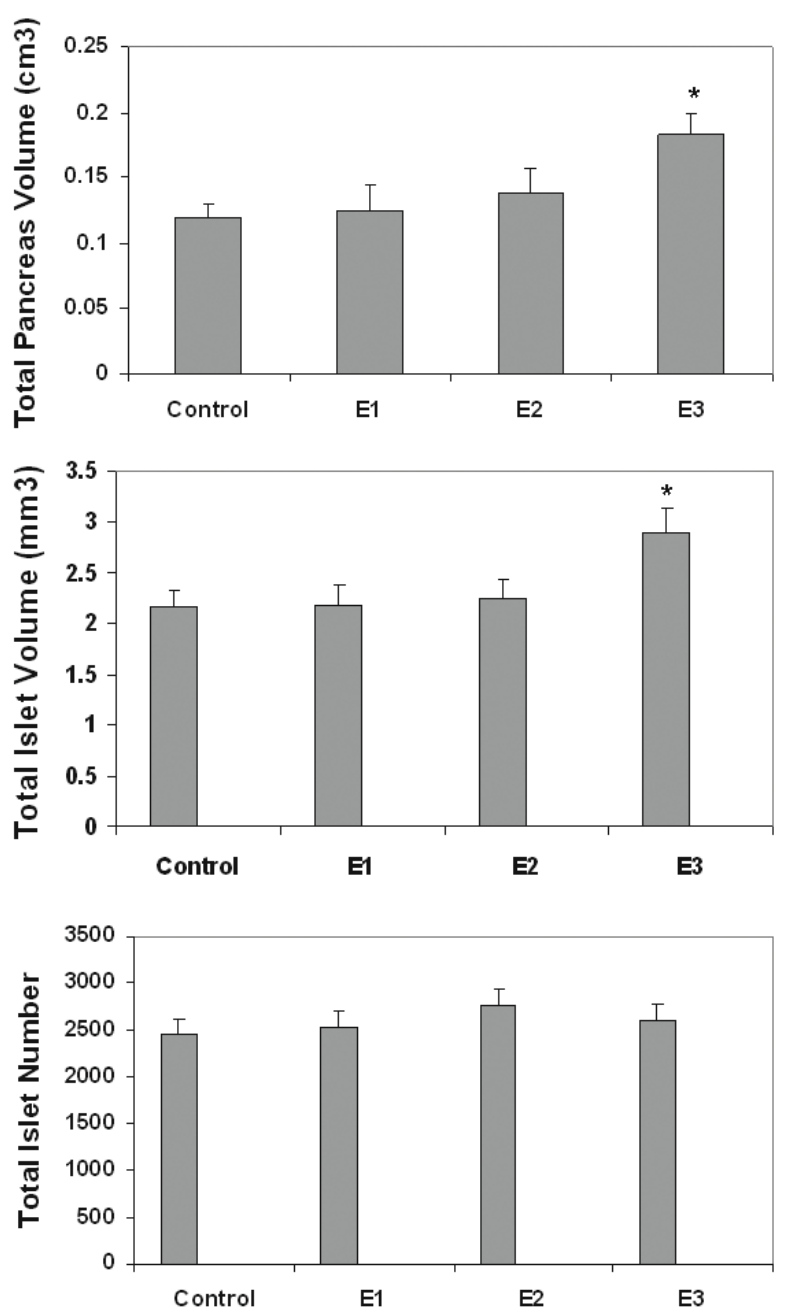

Fig. 4. Total pancreas volume, total islet volume and total islet numbers of control and experimental groups. Values are expressed as means \pm SD for 8 mice. ${ }^{*} \mathbf{p}<0.05$ compared to control group.

In E1 group, total islet volume and total pancreas volume were similar to those in control group. Total islet numbers were also similar to that in control group. Pancreas tissue showed normal architecture.

In E2 group, total islet volume and total pancreas volume were slightly increased $(p>0.05)$. Total islet numbers were similar to that in control group. No histopathological changes were observed in this group.

In E3 group, total pancreas volume was significantly higher than in control group $(p<0.05)$. Total islet volume showed to be significantly increased compared to that in control group $(\mathrm{p}<$ 0.05 ). Total islet numbers were similar to that in control group. No histopathological changes were observed in this group. The results of total islet volume, total pancreas volume, and total islet numbers are depicted in Figure 4.

To determine whether EX-4 affect $\beta$-cell islet function, the expression of Glut-2 and insulin genes were assessed using RT-PCR.

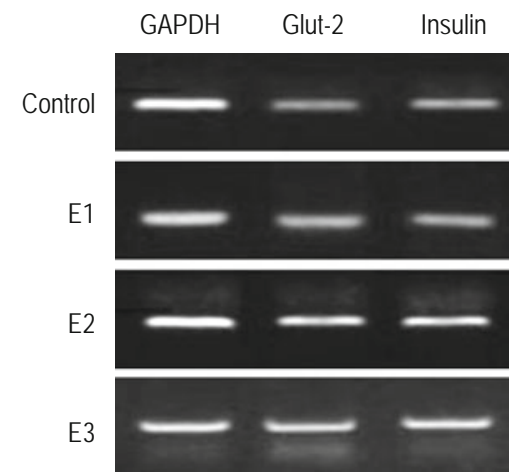

Fig. 5. The expression of insulin and Glut-2 genes in various groups by RT-PCR method are shown.

As illustrated in Figure 5, high expression of Glut-2 and insulin was detected in EX-4 treated mice. Expression of these genes was markedly higher in E2 and E3 groups compared to those in control and E1 groups.

\section{Discussion}

Based on stereological methods (such as fractionators sampling and disector counting) we found an increase in the total volume of islets in the experimental groups, whereas the total number of islets was equal in the four groups with a reasonably narrow confidence interval for the difference of means.

The importance of GLP-1 for stimulation of islet cell proliferation was originally demonstrated in lean 20-day old normoglycemic mice (Edvell et al, 1999). Afterwards, several studies using in vivo models showed that GLP-1 can regulate islet growth mainly by controlling $\beta$-cell neogenesis (1, 7, 27-29). Park et al showed that EX-4 and exercise promotes beta-cell function and mass in islets of diabetic rat (30). Xu et al have also reported that EX-4 increases $\beta$-cell mass (1). Fan et al reported that EX-4 improves blood glucose control in both young and aging normal non-diabetic mice. They showed that EX-4 treatment improved glycemic control in both 3-month and 20 to 22-month old mice. In both groups of mice, the blood glucose lowering effect was independent of beta cell function as indicated by unchanged beta cell proliferation, insulin secretion or beta cell mass (31). However, high expression of Insulin 2 and glut-2 genes in EX-4 treated cells was shown in present study. In pancreatic $\beta$-cells, the glucose uptake is controlled by Glut- 2 , which is essential in the mechanism of glucose-induced insulin secretion (32). Glut- 2 is the glucose sensor of $\beta$ cells leading to the production of insulin (33). GLP-1 increases insulin secretion and the biosynthesis of important $\beta$-cell products besides insulin, namely glucokinase and Glut-2 glucose transporters (34). The increase in expression of these genes probably induces an abnormally elevated secretion of insulin and causes hypoglycemia in nondiabetic animals.

As mentioned above in this study, the volume of islets was increased in EX-4 treated mice. One mechanism responsible for the expansion of islet mass is the inhibition of apoptosis $(19,35,36)$. 
It has also been shown that human islets treated with GLP-1 have a down-regulation of caspase- 3 at the levels of mRNA of the active protein and up-regulation of the anti-apoptotic protein $\mathrm{Bcl}-2$ (35). A second mechanism responsible for the expansion of $\beta$-cell mass is the enhanced cell proliferation or neogenesis.

Tourrel et al by using a recognized model of $\beta$-cells regeneration (neonatalWistar rats injected with streptozotocin, so-called n0-STZ), showed that GLP-1 and Exendin-4 applied during the neonatal period strongly stimulate $\beta$-cell regeneration mainly by $\beta$-cell neogenesis (29). Furthermore, treatment of diabetic GotoKakizaki (GK) rats with GLP-1 or Exendin-4 from day 2 to day 6 after birth resulted in stimulation of $\beta$-cell neogenesis and proliferation with persistent expansion of $\beta$-cell mass detected at adult age (28). However, this study revealed that EX-4 caused no change in the islets number. This indicates that EX-4 has no neogenesis effect on islet's cells in non-diabetic adult animals.

It has been stated in literature review that new islets do develop under certain experimental conditions such as after partial pancreatectomy, where the formation of new islets has been clearly demonstrated (20). Other anatomical structures such as kidney glomeruli also lack the ability of hyperplasia and with an increased demand become hypertrophic instead, probably because of the highly specific structure of the neurovascular and tubular systems necessary for appropriate function. Possibly, the architecture (i.e. the intra-islet vascular structure) of the islets is complex to a degree that it only allows new islets to be formed during the formation, growth, or regeneration of the pancreas during fetal life or after partial pancreatectomy (23).

Nachnani et al evaluated the histological and biochemical effects of EX-4 on the pancreas in rats. They showed that animals treated with exendin-4 had pancreatic acinar inflammation, pyknotic nuclei and weighed significantly less than control rats (20). However, in this study no evidences of pancreatic acinar inflammation or histopathological changes were observed.

\section{Conclusion}

In this study we demonstrated that EX-4 increased the pancreas and islet volume in non-diabetic mice. The increased total islet mass is probably caused by islet hypertrophia without the formation of additional islets. In this study we also revealed that EX-4 can enhance the expression of insulin and Glut-2 genes which may induce hypoglycemia in non-diabetic mice. Further experiments are needed to clarify the exact mechanism of islet hypertrophy induced by EX-4 and other GLP-1 agonists.

\section{References}

1. Xu G, Stoffers DA, Habener JF, Bonner-Weir S. Exendin-4 stimulates both b-Cell replication and neogenesis, resulting in increased b-Cell mass and improved glucose tolerance in diabetic rats. Diabetologia 1999; 48 (12): 2270-2276.

2. Hui R, Wright C, Perfetti R. Glucagon-like peptide 1 induces differentiation of islet duodenal homeobox-1 positive pancreatic ductal cells into insulin-secretion cells. Diabetes 2001; 50 (4): 785-796.
3. Abraham EJ, Leech CA, Lin JC, Zulewski H, Habener JF. Insulinotropic hormone glucagon-like peptide-1 differentiation of human pancreatic islet-derived progenitor cells into insulin producing cells. Endocrinology 2002; 143 (8): 3152-3161.

4. Hardikar AA, Wang XY, William L, Kwok J, Wong R, Tuch BE. Functional maturation of fetal porcine beta cells by glucagon-like peptide 1 and cholecystokinin. Endocrinology 2002; 143 (9): 3505-3514.

5. Kieffer TJ, Mcintosh CH, Pederson RA. Degradation of glucose-dependent insulinotropic polypeptide and truncated glucagon-like peptide-1 in vitro and invivo by dipeptidyl peptidase IV. Endocrinology 1995; 136 (8): 3585-3596.

6. Zhou J, Wang Y, Pineyro MA, Egan JM. Glucagon-like peptide 1 and exendin-4 convert pancreatic AR42J cells into glucagon- and insulinproducing cells. Diabetes 1999; 48 (12): 2358-2366.

7. Stoffers, DA, Kieffer TJ, Hussain MA, Drucker DJ, Bonner-Weir S, Habner JF, Egan JM. Insulinotropic glucagon-like peptide 1 agonists stimulate expression of homeodomain protein IDX-1 and increase islet size in mouse pancreas. Diabetes 2004; 49 (5): 741-748.

8. Kastin AJ, Akerstrom V. Entry of exendin-4 into brain is rapid but may be limited at high doses. Int J Obes Relat Metab Disord 2003; 27 (3): $313-318$.

9. De Fronzo RA, Ranter RE, Han J, Kim DD, Fineman MS, Baron AD. Effects of exenatide (exendin-4) on glycemic control and weight over 30 weeks in metformin-treated patients with type 2 diabetes. Diabetes Care 2005; 28 (5): 1092-1100.

10. Buse JB, Henry RR, Han J, Kim DD, Fineman MS, Baron AD. Effects of exenatide (exendin-4) on glycemic control over 30 weeks in sulfonylurea-treated patients with type 2 diabetes. Diabetes Care 2004; 27 (11): 2628-2635.

11. Kendall DM, Riddle MC, Rosenstock J, Zhuang D, Kim DD, Fineman, MS, Baron AD. Effects of exenatide (exendin-4) on glycemic control over 30 weeks in patients with type 2 diabetes treated with metformin and a sulfonylurea. Diabetes Care 2005; 28 (5): 1083-1091.

12. Blonde L, Klein EJ, Han J, Zhang B, Mac SM, Poon TH, Taylor KL et al. Interim analysis of the effects of exenatide treatment on A1C, weight and cardiovascular risk factors over 82 weeks in 314 overweight patients with type 2 diabetes. Diabetes Obes Metab 2006; 8 (4): 436-447

13. Buse JB, Klonoff DC, Nielsen LL, Guan X, Bowlus CL, Holcombe JH, Maggs DG et al. Metabolic effects of two years of exenatide treatment on diabetes, obesity, and hepatic biomarkers in patients with type 2 diabetes. Clin Ther 2007; 29 (1): 139-153.

14. Perry T, Haughey NJ, Mattson MP, Egan JM, Grieg NH. Protection and reversal of excitotoxic neuronal damage by glucagon-like peptide-1 and exendin-4. J Pharmacol Exp Ther 2000a; 302 (3): 881-888.

15. Perry T, Lahiri DK, Chen D, Zhou J, Shaw KT. A novel neurotrophic property of glucagon-like peptide 1: a promoter of nerve growth factor-mediated differentiation in PC12 cells. J Pharmacol Exp Ther 2002b; 300 (3): 958-966.

16. During MJ, Cao L, Zuzga DS, Francis JS, Fitzimons HL, Jiao X. Glucagon-like peptide-1 receptor is involved in learning and neuroprotection. Nat Med 2003; 9 (9): 1173-1179.

17. Vella A, Shan P, Reed AS, Adkins AS, Basu R, Rizza RA. Lack of effect of exendin-4 and glucagon-like peptide-1-(7,36)-amide on insulin action in non-diabetic humans. Diabetologia 2002; 45 (10): 1410-1415. 
18. Ranta F, Ayram D, Berchtold S, Adkins AS, Basu R, Rizza RA. Dexamethasone induces cell death in insulin-secreting cells, an effect reversed by exendin-4. Diabetes 2006; 55 (5): 1380-1390.

19. Chen YH, Wang JH, Li ZQ, Yi ZH. Effects of exendin-4 on rat cardiomyocyte apoptosis early after severe scald injury. Nan. Fang. Yi Ke Da Xue Xue Bao 2011; 31 (6): 1101-1104.

20. Nachnani JS, Bulchandani DG, Nookala A, Herndon B, Molteni A. Biochemical and histological effects of exendin-4 (exenatide) on the rat pancreas. Diabetologia 2010; 53 (1): 153-159.

21. Briyal S, Gulati K, Gulati A. Repeated administration of exendin-4 reduces focal cerebral ischemia-induced infarction in rats. Brain Res 2012; 1427: 23-34.

22. Gundersen HJ, Jensen EB. The efficiency of systematic sampling in stereology and its prediction. J Microsc 1987; 147 (3): 229-263.

23. Bock T, Pakkenberg B, Buschard K. Inctrased islet volume but unchanged islet number in ob/ob mice. Diabetes 2003; 52 (7): 1716-1722.

24. Nyengaard JR. Stereologic methods and their application in kidney research. J Am Soc Nephrol 1999; 10 (5): 1100-1123.

25. Sun Y, Zhang L, Gu HF, Han W, Ren M, Wang F, et al. Peroxisome proliferator-activated receptor-1 regulates the expression of pancreatic/ duodenal homeobox-1 in rat Insulinoma (INS-1) cells and ameliorates glucose-induced insulin secretion impaired by palmitate. Endocrinology 2007; 149 (2): 662-671.

26. Edwel A, Lindstrom P, Edvell A. Initiation of increased pancreatic islet growth in young normoglycemic mice (Umea $+/$ ?). Endocrinology 1999; 140 (2): 778-783.

27. Perfetty R, Zhou J, Doyle ME, Egan JM. Glucagon-like peptide-1 induces cell proliferation and pancreatic-duodenum homeobox-1 expression and increases endocrine cell mass in the pancreas of old, glucoseintolerant rats. Endocrinology 2000; 141 (12): 4600-4605.
28. Tourrel C, Bailbe D, Lacome M, Meile MJ, Kergoat M, Portha B. Persistent improvement of type 2 diabetes in the Goto-Kakizaki rat model by expansion of the beta-cell mass during the prediabetic period with glucagon-like peptide-1 or exendin-4. Diabetes 2002; 51 (5): 1443-1452.

29. Tourrel C, Bailbe, D, Meile MJ, Kergoat M, Portha B. Glucagon-like peptide-1 and exendin-4 stimulate beta cell neogenesis in streptozotocintreated newborn rats resulting in persistently improved glucose homeostasis at adult age. Diabetes 2001; 50 (7): 1562-1570.

30. Park S, Hong SM, Sung SR. Exendin- 4 and exercise promotes betacell function and mass through IRS2 induction in islets of diabetic rats. Life Sci 2008; 82 (9-10): 503-511.

31. Fan R, Kang Z, He L, Chan J, Xu G. Exendin-4 improves blood glucose control in both young and aging normal non-diabetic mice, possible contribution of beta cell independent effects. PIOS One 2011; 6 (5): e20443.

32. Olson AL, Pessin JE. Structure function, and regulation of the mammalian facilitative glucose transporter gene family. Annu Rev Nutr 1993; 16: $235-256$.

33. Lopes Da Costa C, Sampaio De Freitas M, Sanches Moura A. Insulin secretion and GLUT-2 expression in undernourished neonate rats. J Nutr Biochem 2004; 15 (4): 236-241.

34. Verspohl EJ. Novel therapeutics for type 2 diabetes: Incretin hormone mimetics (glucagon-like peptide-1 receptor agonists) and dipeptidyl peptidase-4 inhibitors. Pharmacol Ther 2009; 124 (1): 113-138.

35. Farilla L, Bulotta A, Hirshberg B, Li Calzi S, Khoury N, Noushmehr $\mathbf{H}$ et al. Glucagon-like peptide1 inhibits cell apoptosis and improves glucose responsiveness of freshly isolated human islets. Endocrinology 2003; 144 (12): 5149-5158.

Received February 6, 2013. Accepted May 10, 2013. 